\title{
Short communication: Investigation of the temporal relationships between milk mid-infrared predicted biomarkers and lameness events in later lactation
}

\author{
Axelle Mineur, ${ }^{1}$ Hedi Hammami, ${ }^{1}$ Clément Grelet, ${ }^{2}$ Christa Egger-Danner, ${ }^{3}$ Johann Sölkner, ${ }^{4}$ \\ and Nicolas Gengler ${ }^{1 *}$ \\ ${ }^{1}$ TERRA Teaching and Research Centre, Gembloux Agro-Bio Tech, University of Liège, 5030 Gembloux, Belgium \\ ${ }^{2}$ Centre Wallon de Recherches Agronomiques (CRA-W), 5030 Gembloux, Belgium \\ ${ }^{3}$ ZuchtData EDV-Dienstleistungen $\mathrm{GmbH}, 1200$ Vienna, Austria \\ ${ }^{4}$ BOKU-University of Natural Resources and Life Sciences, 1180 Vienna, Austria
}

\section{ABSTRACT}

This study reports on the exploration of temporal relationships between milk mid-infrared predicted biomarkers and lameness events. Lameness in dairy cows is an issue that can vary greatly in severity and is of concern for both producers and consumers. Metabolic disorders are often associated with lameness. However, lameness can arise weeks or even months after the metabolic disorder, making the detection of causality difficult. We already use mid-infrared technology to predict major milk components, such as fat or protein, during routine milk recording and for milk payment. It was recently shown that this technology can also be used to predict novel biomarkers linked to metabolic disorders in cows, such as oleic acid (18:1 cis-9), $\beta$-hydroxybutyrate, acetone, and citrate in milk. We used these novel biomarkers as proxies for metabolic issues. Other studies have explored the possibility of using mid-infrared spectra to predict metabolic diseases and found it (potentially) usable for indicating classes of metabolic problems. We wanted to explore the possible relationship between mid-infrared-based metabolites and lameness over the course of lactation. In total, data were recorded from 6,292 cows on 161 farms in Austria. Lameness data were recorded between March 2014 and March 2015 and consisted of 37,555 records. Mid-infrared data were recorded between July and December 2014 and consisted of 9,152 records. Our approach consisted of fitting preadjustments to the data using fixed effects, computing pair-wise correlations, and finally applying polynomial smoothing of the correlations for a given biomarker at a certain month in lactation and the lameness events scored on severity scale from sound or non-lame (lameness score of 1) to severely lame (lameness score of 5) throughout

Received April 18, 2019.

Accepted December 23, 2019.

*Corresponding author: nicolas.gengler@uliege.be the lactation. The final correlations between biomarkers and lameness scores were significant, but not high. However, for the results of the present study, we should not look at the correlations in terms of absolute values, but rather as indicators of a relationship through time. When doing so, we can see that metabolic problems occurring in mo 1 and 3 seem more linked to longterm effects on hoof and leg health than those in mo 2 . However, the quantity (only 1 pair-wise correlation exceeded 1,000 observations) and the quality (due to limited data, no separation according to more metabolic-related diseases could be done) of the data should be improved.

Key words: metabolic disorder, mid-infrared spectrometry, Fisher transformation, polynomial smoothing

\section{Short Communication}

An important issue in dairy cattle management, but also breeding, is to predict future potential disturbances before they occur. To develop tools to predict future events, knowledge of the temporal relationships between earlier indicators and these events is necessary. Lameness is a major problem in the dairy industry today, impairing sustainability because it has animal health and therefore economic and ethical implications. Despite all of this, the tools to reduce lameness that are available to farmers mostly rely on detection of lame animals, enabling veterinary care for the affected cow. However, preventing a lameness event would be better than curing it, both from an economic point of view and from a veterinary perspective. The development of method for the prediction of lameness could therefore be of use to the dairy industry. Although we will probably never be able to predict the types of lameness caused by impacts or other exterior factors, lameness related to internal causes such as metabolic disorders could be predictable to a certain extent. Metabolic disorders are an important cause of lameness problems. They can 
cause thinning of the digital cushion and increased risk of wounds (e.g., abscess or ulcers, white line disease) and infections (e.g., dermatitis digitalis; Bicalho et al., 2009). Secondary consequences of metabolic disorders also include influences on the health (Pryce et al., 2016), behavior, feeding, and performance of cows, such as their milk yield (Onyiro et al., 2008). Fat and protein content, as well as the fine milk composition of cows affected by metabolic disorders, can also be influenced (Gengler et al., 2016). Grelet et al. (2019) used this knowledge to explore the possibility of using midinfrared (MIR) spectra to predict metabolic diseases and found it (potentially) usable for indicating classes of metabolic problems: that is, healthy, moderately affected or highly affected ( $74 \%$ of observations correctly discriminated) or healthy and moderately affected compared with highly affected (92\% correct classification).

Interestingly, an important aspect of lameness caused by a metabolic disorder is that the causal relationship can spread over time, linking early-lactation metabolic disorders with later-lactation lameness. However, most studies have focused on how lameness can cause a cow to lose body condition and even fall into metabolic problems; the other causal direction (i.e., using the physical or metabolic state of the cow to predict potential lameness) has rarely been investigated. The present study investigated the temporal relationships between milk MIR-predicted biomarkers and lameness events as a first exploration into the possibility of using MIR to predict lameness events.

Studies into the relationship between lameness, BCS, and milk yield or major milk components have been conducted previously (Green et al., 2014; Lim et al., 2015). These studies used mixed-effect binomial, continuous outcome, and multilevel multistate discrete time models. All of these models are based on the hypothesis that a given event (i.e., lameness) can be explained by a potentially very large group of explanatory variables. The results obtained provided important findings, but they did not model the potential causal relationship spreading across time, linking early-lactation metabolic problems with later-lactation lameness. It is also well known that the mobilization of body reserves and lowering of BCS can be linked to an increase in the production of certain metabolites (Grelet et al., 2019). Suthar et al. (2013) found that cows with subclinical ketosis had an increased risk of lameness. Calderon and Cook (2011) found a significant difference in blood BHB concentrations between sound and lame cows, and Bhadauria et al. (2015) studied the possibility of lowering the elevated blood BHB levels in lame cows.

The concentrations of certain metabolites in the blood are translated into concentrations in milk (Gengler et al., 2016), creating a potential link between fine milk composition (Hamann and Krömker, 1997; Gengler et al., 2016), animal health, and lameness (Heringstad et al., 2018).

In their research, Denis-Robichaud et al. (2014) found that milk BHB and milk acetone had good correlations with blood BHB ( $\mathrm{r}=0.89$ and 0.73 , respectively). Similarly, van Knegsel et al. (2010) found milk acetone or milk BHB to be better suited for the detection of hyperketonemia (blood BHB $\geq 1.2 \mathrm{mmol} / \mathrm{L}$ ) than milk fat-protein ratio. Van Haelst et al. (2008) found elevated levels of oleic acid (18:1 cis-9) in milk fat to be associated with a hyperketonemia diagnosis 2 weeks later, but Jorjong et al. (2014) found that cows with at least $240 \mathrm{~g} / \mathrm{kg}$ of oleic acid (18:1 cis-9) in milk fat had a $50 \%$ increased risk of plasma fatty acids $\geq 0.6 \mathrm{mmol} / \mathrm{L}$, fatty acids being used as an indicator for ketosis. An increase in oleic acid (18:1 cis-9) has also been strongly linked to early-lactation negative energy balance and the release of fat reserves (Bastin et al., 2011). Studies have also used milk metabolites such as acetone, citrate, and BHB to provide information on metabolic status and potential ketosis (Grelet et al., 2016). Next to negative energy balance and ketosis, acidosis, and SARA are also important factors in the development of lameness. Kleen et al. (2013) found a tendency for a proportionally higher number of lame cows in herds with low ruminal $\mathrm{pH}$, indicative of SARA. Cook et al. (2004) determined that acidosis was a factor in the onset of lameness. Enemark (2008) and Abdela (2016) agreed with the increased risk of lameness in cows with SARA.

However, to our knowledge no studies have yet tried to link fine milk components (hereafter called biomarkers) and lameness problems over time. The potential research into and use of fine milk composition is hampered by difficulties in obtaining this type of data. As outlined by several authors (e.g., Gengler et al., 2016), MIR-predicted fine milk composition can be used to define MIR-based biomarkers that are available on a large scale and regularly throughout lactation.

Data for this research was collected during the Austrian Efficient Cow project, recording a large range of health-related data from dairy cows on Austrian farms. Although the Efficient Cow project data have also been used to evaluate the use of lameness scores for genetic improvement (Köck et al., 2019), in the present study we focused more on the management application of lameness scores (LS), starting with exploration of the temporal relationship between biomarkers and LS. Data were collected from several breeds. For our research, we used the 3 major Austrian dairy breeds: Simmental (locally called Fleckvieh), Brown-Swiss (locally called Braunvieh), and Holstein. The number of records, animals, and herds per breed are described 
Table 1. Number of records per breed, animals per breed, and number of herds with at least 1 animal of the indicated breed

\begin{tabular}{|c|c|c|c|c|c|c|}
\hline \multirow[b]{2}{*}{ Records } & \multicolumn{2}{|c|}{ Records } & \multicolumn{2}{|c|}{ Animals } & \multicolumn{2}{|c|}{ Herds $^{1}$} \\
\hline & $\mathrm{n}$ & $\%$ & $\mathrm{n}$ & $\%$ & $\mathrm{n}$ & $\%$ \\
\hline Simmental & 27,636 & 61 & 3,753 & 60 & 113 & 70 \\
\hline Brown-Swiss & 10,022 & 22 & 1,473 & 23 & 56 & 35 \\
\hline Holstein & 7,336 & 16 & 1,066 & 17 & 58 & 36 \\
\hline Total & 44,994 & 100 & 6,292 & 100 & 161 & 100 \\
\hline
\end{tabular}

${ }^{1}$ Herds could contain multiple breeds, so the number of herds for each breed does not equal the total number of herds.

in Table 1. The data cover a variety of housing systems, including slatted floors or not; straw or mats; and access to a paddock, a pasture, both, or neither. Lameness data were recorded between March 2014 and March 2015, and MIR data were recorded between July and December 2014 to recover standardized MIR milk sampling (Grelet et al., 2015). Using prediction equations developed by Gembloux Agro-Bio Tech and CRA-W (Soyeurt et al., 2011; Grelet et al., 2016), we obtained MIR-based predictions for the following biomarkers: oleic acid (18:1 cis-9), BHB, acetone, and citrate in milk. Spectra with a Mahalanobis (also called GH) distance (Whitfield et al., 1987) of greater than 5 were considered outliers and deleted. Predictions of fat, protein, and urea were also checked, and 3 records were deleted because of negative urea estimates. It is important to note that the taking of milk samples did not have to coincide with the date of lameness scoring for inclusion in the data set, but only records that included a lameness or milk sample record or both were kept. Only data recorded during the first $305 \mathrm{~d}$ of lactation were retained. We created 10 monthly lactation month classes, the first 9 with $30 \mathrm{~d}$ and the 10th with $35 \mathrm{~d}$. Lameness scores were recorded by 32 trained scorers. Cows had to walk in a straight line on a hard, smooth surface (often concrete) and were scored using a scale of 1 to 5 : $1=$ sound, $2=$ mildly lame, $3=$ moderately lame, $4=$ lame, and $5=$ severely lame. More details on data recording are given by Mineur et al. (2017). Animals could be observed in different lactations,
Table 2. Number of records containing lameness scores or midinfrared spectra, and the total number of records

\begin{tabular}{|c|c|c|c|c|c|c|}
\hline \multirow[b]{2}{*}{ Records } & \multicolumn{2}{|c|}{$\begin{array}{l}\text { Lameness } \\
\text { scores }\end{array}$} & \multicolumn{2}{|c|}{$\begin{array}{l}\text { Mid-infrared } \\
\text { spectra }\end{array}$} & \multicolumn{2}{|c|}{ Total $^{1}$} \\
\hline & $\mathrm{n}$ & $\%$ & $\mathrm{n}$ & $\%$ & $\mathrm{n}$ & $\%$ \\
\hline Simmental & 22,615 & 60 & 6,388 & 70 & 27,636 & 61 \\
\hline Brown-Swiss & 8,805 & 23 & 1,381 & 15 & 10,022 & 22 \\
\hline Holstein & 6,135 & 16 & 1,383 & 15 & 7,336 & 16 \\
\hline Total & 37,555 & 100 & 9,152 & 100 & 44,994 & 100 \\
\hline
\end{tabular}

${ }^{1}$ Some records had lameness scores and biomarkers on the same DIM, so the totals for lameness scores and mid-infrared spectra do not equal the total number of records.

so we divided lactations into 3 groups: first, second, and third or subsequent lactations. We used the test dates, respectively scoring dates to establish seasons (i.e., spring, summer, fall, and winter, the 4 seasons of the European continental climate found in Austria). Contemporary groups were based on herd-year-seasons. We dropped records with less than 4 records in a given herd-year-season class. After these edits, a total of 9,152 records containing MIR spectra information and 37,555 records containing lameness score values were retained, as shown in Table 2. The distribution of LS per breed is given in Table 3, and the distribution of LS per number of lactation is given in Table 4. Descriptive statistics of the biomarkers are given in Table 5 .

We used R (R Core Team, 2018) for data cleaning and preparation as described above. Using F-test Type 3 statistics provided by SAS (version 9.4; SAS Institute Inc., 2017), we identified the fixed factors that were significant for lameness score and MIR-based biomarkers. The significant factors were herd-year-season, breed, and lactation groups for lameness score. For biomarker concentration, the significant factors were herd-yearseason, breed, and month class. We then corrected LS and biomarkers for these factors using a single-trait fixed-effect model for LS and a 4-trait multivariate fixed-effect model for biomarkers. For this, we used the BLUPF90 family of programs (Ignacy Misztal, 2008). We estimated residual (co)variances between oleic acid (18:1 cis-9), BHB, acetone, and citrate using expecta-

Table 3. Distribution of lameness scores per breed

\begin{tabular}{|c|c|c|c|c|c|c|c|}
\hline \multirow{2}{*}{$\begin{array}{l}\text { Lameness } \\
\text { score }^{1}\end{array}$} & \multicolumn{2}{|c|}{ Brown-Swiss } & \multicolumn{2}{|c|}{ Simmental } & \multicolumn{2}{|c|}{ Holstein } & \multirow[b]{2}{*}{ Total } \\
\hline & $\mathrm{n}$ & $\%$ & $\mathrm{n}$ & $\%$ & $\mathrm{n}$ & $\%$ & \\
\hline 1 & 7,297 & 83 & 17,840 & 79 & 4,334 & 71 & 29,471 \\
\hline 2 & 1,007 & 10 & 3,307 & 15 & 1,297 & 21 & 5,611 \\
\hline 3 & 352 & 4 & 985 & 4 & 370 & 6 & 1,707 \\
\hline 4 & 122 & 1 & 423 & 2 & 114 & 2 & 659 \\
\hline 5 & 27 & 0 & 60 & 0 & 20 & 0 & 107 \\
\hline Total & 8,805 & 100 & 22,615 & 100 & 6,135 & 100 & 37,555 \\
\hline
\end{tabular}

${ }^{1}$ Lameness scores: $1=$ sound; $2=$ mildly lame; $3=$ moderately lame; $4=$ lame; $5=$ severely lame. 
Table 4. Distribution of lameness scores for first, second and subsequent lactations

\begin{tabular}{|c|c|c|c|c|c|c|c|}
\hline \multirow{2}{*}{$\begin{array}{l}\text { Lameness } \\
\text { score }^{1}\end{array}$} & \multicolumn{2}{|c|}{ Lactation 1} & \multicolumn{2}{|c|}{ Lactation 2} & \multicolumn{2}{|c|}{ Lactation $3+$} & \multirow[b]{2}{*}{ Total } \\
\hline & $\mathrm{n}$ & $\%$ & $\mathrm{n}$ & $\%$ & $\mathrm{n}$ & $\%$ & \\
\hline 1 & 9,645 & 90 & 6,822 & 83 & 13,004 & 70 & 29,471 \\
\hline 2 & 786 & 7 & 1,100 & 13 & 3,725 & 20 & 5,611 \\
\hline 3 & 173 & 2 & 220 & 3 & 1,314 & 7 & 1,707 \\
\hline 4 & 62 & 1 & 68 & 1 & 529 & 3 & 659 \\
\hline 5 & 14 & 0 & 12 & 0 & 81 & 0 & 107 \\
\hline Total & 10,680 & 100 & 8,222 & 100 & 18,653 & 100 & 37,555 \\
\hline
\end{tabular}

${ }^{1}$ Lameness scores: $1=$ sound; $2=$ mildly lame; $3=$ moderately lame; $4=$ lame; $5=$ severely lame.

tion maximization (EM)-REML. We corrected data by adjusting these validated fixed-effect models and extracting the residuals as the deviations from the observed to the expected values. Using R ( R Core Team, 2018), we then estimated the pair-wise Pearson correlations between LS and the MIR-based biomarkers. We did this in 10 monthly blocks of mean residuals per month in lactation. In this way, we obtained a $10 \times 10$ matrix of correlation values between each biomarker and lameness core ranging from mo 1 to mo 10.

We used a weighted smoothing algorithm, because the number of pair-wise combinations per correlation value varied greatly. Weighted smoothing would give the same weight to all smoothed correlations and allow for better visualization of the evolution of these correlations over time. We applied the smoothing throughout the lactation, involving the correlations for each biomarker of a given lactation month with the lameness score for all lactation months. Smoothing of this lactation curve of correlations used a fourth-order Legendre polynomial function after applying a Fisher z-transform (Fisher, 1915) on the correlations and weighting each value with the inverse of the sampling error variance, $N$ - 3 (Gayen, 1951), where $N$ was the number of observations used to compute this correlation. If $N$ was 3 or lower, we put the weight to zero. We computed upperand lower-bound transformed correlations by, respectively, adding or subtracting $1 / \sqrt{(N-3)}$ from the $z^{-}$ transformed correlations before smoothing. If $N$ was 3 or lower, the associated transformed correlation had a weight of zero and was not considered in the smoothing process. We then smoothed the upper- and lower-bound correlations using the same approach (lactation curve of z-transformed correlations), this time applied to, respectively, an upper or lower lactation curve of correlations. The choice of the fourth order was empirically based on approximate $t$-tests of the regression coefficients generated during the smoothing procedure. The proposed smoothing strategy can be considered equivalent to using (co)variance functions as defined by Kirkpatrick et al. (1990), but directly modeling z-transformed correlation coefficients. We then back-transformed smoothed z-values (lower, intermediate, and upper) to correlations. We tested the hypothesis that a given correlation was different from zero using t-test statistics associated with a large number of degrees of freedom, because the number of observations used in the smoothing process was at least 2,428 , the sum of the first row in Table 6.

We have reported correlations among the 4 biomarkers [oleic acid (18:1 cis-9), BHB, acetone and citrate] in Table 7 . We estimated these correlations as residual (co)variances after fitting the fixed-effect models. Despite rather high correlations, oleic acid (18:1 cis-9) distinguished itself from BHB, acetone, and especially citrate. This was also confirmed by principal components analysis showing that approximately $66 \%$ of the variation was common, and the rest defined largely by the opposition between oleic acid (18:1 cis-9) and citrate $(19 \%)$.

In Table 8, we have reported the differences in means for the 4 biomarkers between milk samples from cows that would need treatment for lameness issues (i.e., with a lameness score of 3,4 , or 5 ) and cows that would not (i.e., with a lameness score of 1 or 2). These differences were significant for oleic acid and citrate.

Table 5. Univariate descriptive statistics for the biomarkers oleic acid, BHB, acetone, and citrate

\begin{tabular}{|c|c|c|c|c|c|c|c|}
\hline Biomarker & Minimum & Median & Maximum & Range & Mean & SD & Variance \\
\hline Acetone, $\log _{\mathrm{mmol} / \mathrm{L}}$ & 0.01 & 0.05 & 0.54 & 0.53 & 0.06 & 0.03 & 0.00 \\
\hline
\end{tabular}


Table 6. Number of pair-wise combination values for each month combination ${ }^{1}$ (number of pair-wise combinations with a lameness score $>1$ )

\begin{tabular}{|c|c|c|c|c|c|c|c|c|c|c|}
\hline \multirow[b]{2}{*}{ Biomarker, mo } & \multicolumn{10}{|c|}{ Lameness score, mo } \\
\hline & 1 & 2 & 3 & 4 & 5 & 6 & 7 & 8 & 9 & 10 \\
\hline 1 & $\begin{array}{c}747 \\
(159)\end{array}$ & $\begin{array}{l}424 \\
(93)\end{array}$ & $\begin{array}{l}432 \\
(79)\end{array}$ & $\begin{array}{l}367 \\
(60)\end{array}$ & $\begin{array}{l}236 \\
(47)\end{array}$ & $\begin{array}{l}143 \\
(29)\end{array}$ & $\begin{array}{c}63 \\
(12)\end{array}$ & $\begin{array}{l}13 \\
(2)\end{array}$ & $\begin{array}{c}3 \\
(0)\end{array}$ & $\begin{array}{c}0 \\
(0)\end{array}$ \\
\hline 2 & 575 & $\begin{array}{c}1,019 \\
(259)\end{array}$ & $\begin{array}{c}647 \\
(155)\end{array}$ & $\begin{array}{c}537 \\
(132)\end{array}$ & $\begin{array}{l}457 \\
(93)\end{array}$ & $\begin{array}{l}261 \\
(55)\end{array}$ & $\begin{array}{l}146 \\
(34)\end{array}$ & $\begin{array}{c}79 \\
(10)\end{array}$ & $\begin{array}{c}9 \\
(0)\end{array}$ & $\begin{array}{c}4 \\
(2)\end{array}$ \\
\hline 3 & 487 & 787 & $\begin{array}{c}913 \\
(208)\end{array}$ & $\begin{array}{c}555 \\
(124)\end{array}$ & $\begin{array}{c}492 \\
(96)\end{array}$ & $\begin{array}{l}357 \\
(65)\end{array}$ & $\begin{array}{l}214 \\
(42)\end{array}$ & $\begin{array}{l}150 \\
(32)\end{array}$ & $\begin{array}{c}53 \\
(12)\end{array}$ & $\begin{array}{l}11 \\
(2)\end{array}$ \\
\hline 4 & 507 & 631 & 674 & $\begin{array}{c}817 \\
(209)\end{array}$ & $\begin{array}{c}511 \\
(109)\end{array}$ & $\begin{array}{l}404 \\
(83)\end{array}$ & $\begin{array}{l}311 \\
(52)\end{array}$ & $\begin{array}{l}223 \\
(38)\end{array}$ & $\begin{array}{l}117 \\
(19)\end{array}$ & $\begin{array}{c}65 \\
(10)\end{array}$ \\
\hline 5 & 511 & 671 & 603 & 670 & $\begin{array}{c}808 \\
(201)\end{array}$ & $\begin{array}{c}484 \\
(104)\end{array}$ & $\begin{array}{l}419 \\
(81)\end{array}$ & $\begin{array}{l}356 \\
(68)\end{array}$ & $\begin{array}{l}250 \\
(49)\end{array}$ & $\begin{array}{l}174 \\
(25)\end{array}$ \\
\hline 6 & 457 & 663 & 641 & 606 & 666 & $\begin{array}{c}782 \\
(165)\end{array}$ & $\begin{array}{l}441 \\
(77)\end{array}$ & $\begin{array}{c}445 \\
(85)\end{array}$ & $\begin{array}{l}357 \\
(70)\end{array}$ & $\begin{array}{c}297 \\
(59)\end{array}$ \\
\hline 7 & 437 & 667 & 700 & 674 & 632 & 677 & $\begin{array}{c}793 \\
(177)\end{array}$ & $\begin{array}{c}527 \\
(113)\end{array}$ & $\begin{array}{l}456 \\
(89)\end{array}$ & $\begin{array}{c}454 \\
(76)\end{array}$ \\
\hline 8 & 411 & 611 & 702 & 743 & 708 & 632 & 708 & $\begin{array}{c}849 \\
(205)\end{array}$ & $\begin{array}{c}532 \\
(110)\end{array}$ & $\begin{array}{c}556 \\
(108)\end{array}$ \\
\hline 9 & 308 & 510 & 641 & 683 & 729 & 696 & 631 & 715 & $\begin{array}{c}837 \\
(178)\end{array}$ & $\begin{array}{c}617 \\
(118)\end{array}$ \\
\hline 10 & 221 & 377 & 537 & 576 & 667 & 682 & 680 & 613 & 652 & $\begin{array}{c}864 \\
(191)\end{array}$ \\
\hline
\end{tabular}

${ }^{1}$ Biomarker mo 1 to 10 with lameness score for mo 1 to 10.

Table 6 shows the distribution of observations used to compute the correlations. Because of the experimental design, few data points were available to compare later LS with early biomarkers. This was especially the case for LS in mo 7 to 10 and biomarkers in mo 1 to 4 : some combinations had fewer than 100 records. In the following, results associated with these cases should be considered with caution. We smoothed raw correlations as reported earlier. Detailed results are given in the supplementary material (Supplemental Tables S1, S2, S3, and S4; https://doi.org/10.3168/jds.2019-16826).

The computational strategy detected relevant temporal associations. Indeed, we observed that oleic acid (18:1 cis-9) was the biomarker with the largest number of significant correlations between its corrected values early in lactation and later LS. However, after the first 3 mo of lactation, the standard errors of the correlations become higher than the values of the correlations, suggesting that this temporal relationship was present mostly at the start of lactation, in relation to metabolic problems. It seems that after the initial, startof-lactation metabolic problems, the peak biological

Table 7. Residual correlations $(\mathrm{SE})^{1}$ among the biomarkers oleic acid, $\mathrm{BHB}$, acetone, and citrate

\begin{tabular}{lccc}
\hline Biomarker & BHB & Acetone & Citrate \\
\hline Oleic acid (18:1 cis-9) & $0.48(0.01)$ & $0.57(0.01)$ & $0.27(0.01)$ \\
BHB & & $0.75(0.01)$ & $0.60(0.01)$ \\
Acetone & & & $0.52(0.01)$ \\
\hline
\end{tabular}

${ }^{1}$ After fitting of the fixed-effect models. link between milk composition and lameness problems weakens, and other reasons for lameness start to play a more important role. Figure 1A shows the results over a period of $8 \mathrm{mo}$ in lactation. However, for the present results, we should not view the correlations in terms of (absolute) values, but as indicators of a relationship over time. When doing so, we can see that metabolic problems occurring in mo 1 and 3 seem more linked to long-term effects on hoof and leg health than those in mo 2. We can see that oleic acid (18:1 cis-9) measured in mo 2 showed an increasing correlation during the next $5 \mathrm{mo}$, a potential indicator that increased oleic acid (18:1 cis-9) concentration after 30 DIM is a strong indicator of potential metabolic problems. From a biological point of view, this seems in accordance with dairy cows reaching their lactation peak during that month.

Table 8. Differences in mean (SD) concentrations between sound records (lameness score 1 or 2 ) and lame records (lameness score 3 to 5) for the biomarkers oleic acid, acetone, BHB, and citrate ${ }^{1}$

\begin{tabular}{lcc}
\hline Biomarker & Sound & Lame \\
\hline Oleic acid $(18: 1$ cis-9), & $0.79^{\mathrm{a}}(0.21)$ & $0.87^{\mathrm{b}}(0.27)$ \\
$\mathrm{g} / 100 \mathrm{~mL}$ & $0.0583(0.0297)$ & $0.0589(0.0301)$ \\
Acetone, $\log _{\mathrm{mmol} / \mathrm{L}}$ & $157.58(42.51)$ & $154.37(46.43)$ \\
$\mathrm{BHB}, \log _{\mu \mathrm{mol} / \mathrm{L}}$ & $9.24^{\mathrm{a}}(1.48)$ & $8.65^{\mathrm{b}}(1.62)$ \\
Citrate, $\mathrm{mmol} / \mathrm{L}$ & &
\end{tabular}

$\overline{a, b}$ Values in the same row with different superscripts differed significantly $(P<0.05)$.

${ }^{1}$ Records with lameness score and milk data on the same day were used for this $t$ test (i.e., 1,713 records, of which 1,571 were classified as sound and 142 were classified as lame). 

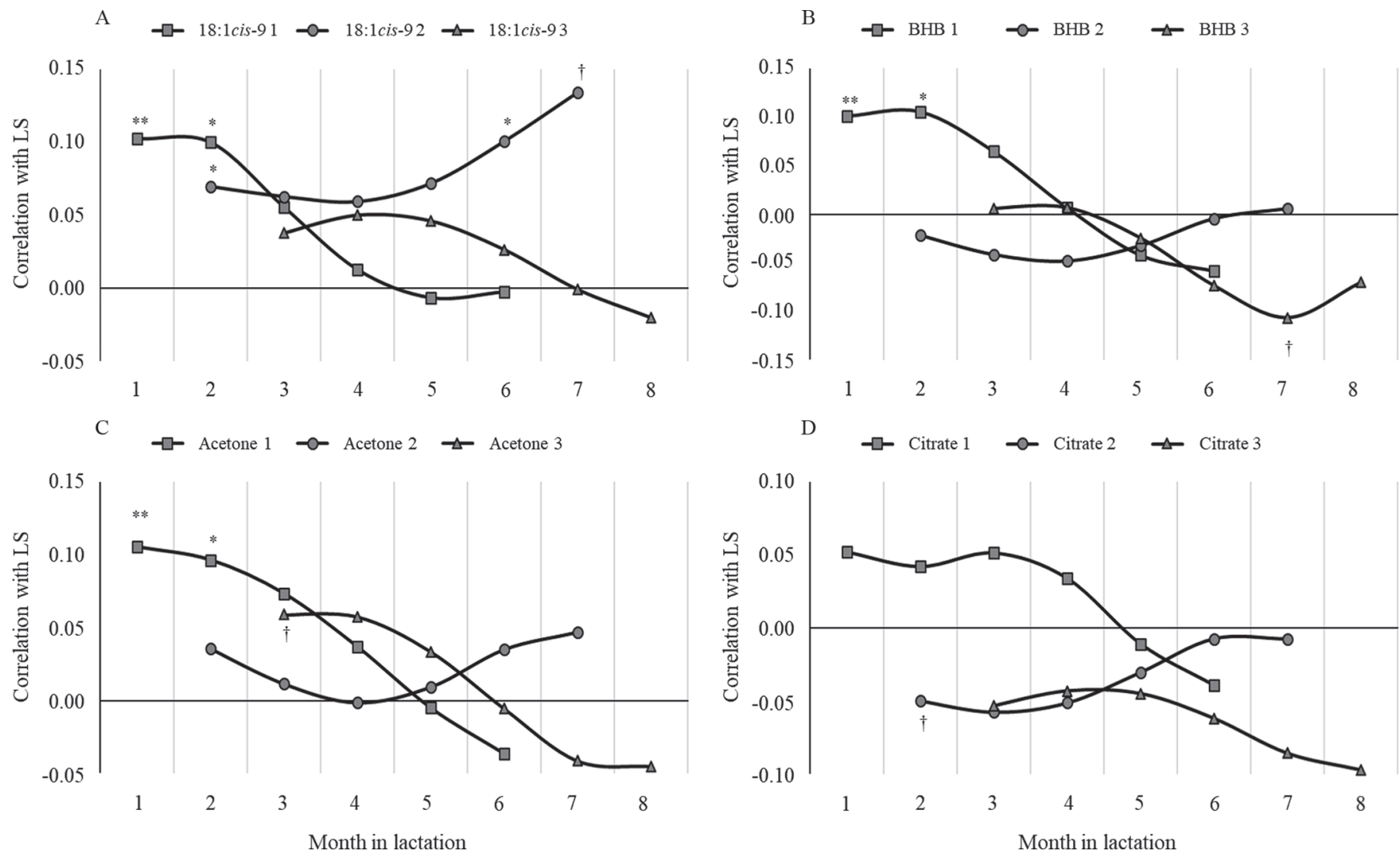

Figure 1. Evolution of the correlations between the biomarkers (A) oleic acid (18:1 cis-9), (B) BHB, (C) acetone, and (D) citrate recorded at mo 1,2 , or 3 and lameness scores (LS) during the following 6 mo. $\dagger P<0.10,{ }^{*} P<0.05,{ }^{* *} P<0.01$.

They are then at high risk of developing negative energy balance and metabolic problems. An increase of oleic acid (18:1 cis-9) in mo 1 or 3 was linked to higher LS in the next month, but then decreased quickly. The results for the 3 other biomarkers in Figure 1B, C, and $\mathrm{D}$ showed very similar patterns in terms of increase or decrease in correlations for each month.

This study showed the potential for the developed computational strategy to assess temporal relationships between milk MIR-predicted biomarkers and lameness events. The results, expressed as correlations between corrected biomarker values and LS over months in lactation showed some time-dependent relationships, especially for oleic acid (18:1 cis-9), whose correlations between metabolite concentrations and LS plateaued for the first 2 mo before dropping in mo 3 . However, at least 3 directions are possible for improvement. First, we used a rather small data set. Therefore, even though disease data were also available to us, we did not split our data set even further, reducing the already small number of observations by pair-wise combinations. However, given the well-known role of metabolic disorders on some hoof diseases (e.g., sole ulcer, toe ulcer, sole hemorrhage, white line disease; Heringstad et al., 2018), we should expect better results when investigating these hoof diseases or their severity directly; lameness as considered here was only an indirect indicator of their presence. With the exception of oleic acid (18:1 cis-9), which is also a well-predicted biomarker, the quality of MIR predictors and their potential ability to detect metabolic disorders may be suboptimal.

Second, the results suggest that the correlations and biological link between metabolic problems and lameness is strongest during the first months of lactation. However, as shown in Table 6, once the records were divided into 10 monthly blocks, only 367 to 1,019 records per block remained. Furthermore, milk samples were taken every $40 \mathrm{~d}$, meaning that some samples were taken days to weeks from the actual moment the cow had a metabolic disorder, further lowering the ability to detect metabolic disorders through MIR analysis. However, research is ongoing and new predictors of these biomarkers and definitions of metabolic status are appearing (Grelet et al., 2019).

Third, the biological explanations behind these correlations may be very complex for certain biomarkers. 
When looking at the literature, we found that an increase in oleic acid (18:1 cis-9) concentration was associated with hyperketonemia and ketosis, but a decrease in oleic acid (18:1 cis-9) concentration was associated with SARA and acidosis, and both these diseases could cause lameness.

An alternative strategy could be to make direct use of spectral data as a global proxy for milk composition and animal status (Soyeurt et al., 2010; Gengler et al., 2016; De Marchi et al., 2018), preventing the use of sometimes contradictory concentrations. The proposed method could then be integrated into a spectral variable selection strategy across lactation stages, similar to other correlation-based strategies presented by several authors (e.g., Fujiwara et al., 2012). Finally, from a more strategic point of view, the contribution of a milk-composition-based prediction algorithm for foot and leg problems, using not only MIR but also other on-farm milk composition sensors, could be of major interest for the management and breeding of dairy cows (Gengler, 2019).

\section{ACKNOWLEDGMENTS}

Axelle Mineur, as research fellow, and Nicolas Gengler, as a former senior research associate, acknowledge the support of the National Fund for Scientific Research (Brussels, Belgium). The authors also acknowledge the support of the European Commission under the Seventh Framework Program for the GplusE project, Grant Agreement FP7-KBBE-613689. The content of the paper reflects only the views of the authors; the Community is not liable for any use that may be made of the information contained in this publication. The study is supported by the project "Efficient Cow" funded by the Austrian Federal Ministry of Agriculture, Forestry, Environment and Water Management (Vienna); the Federations of Austrian Fleckvieh (Zwettl), BrownSwiss (Innsbruck), Holstein (Leoben), the Federation of Austrian Cattle Breeders (Vienna) and the Federal States of Austria. The authors declare that they have no conflicts of interest.

\section{REFERENCES}

Abdela, N. 2016. Sub-acute ruminal acidosis (SARA) and its consequence in dairy cattle: A review of past and recent research at global prospective. Achiev. Life Sci. 10:187-196. https://doi.org/ 10.1016/j.als.2016.11.006.

Bastin, C., N. Gengler, and H. Soyeurt. 2011. Phenotypic and genetic variability of production traits and milk fatty acid contents across days in milk for Walloon Holstein first-parity cows. J. Dairy Sci. 94:4152-4163. https://doi.org/10.3168/jds.2010-4108.

Bhadauria, P., S. S. Lathwal, Y. S. Jadoun, A. P. Ruhil, I. Devi, and R. Gupta. 2015. Effect of transition diet fortification on lameness and blood metabolites in pre- and post- partum lame Karan Fries cows. Indian J. Anim. Sci. 85:1006-1011.
Bicalho, R. C. C., V. S. S. Machado, and L. S. S. Caixeta. 2009. Lameness in dairy cattle: A debilitating disease or a disease of debilitated cattle? A cross-sectional study of lameness prevalence and thickness of the digital cushion. J. Dairy Sci. 92:3175-3184. https: //doi.org/10.3168/jds.2008-1827.

Calderon, D. F., and N. B. Cook. 2011. The effect of lameness on the resting behavior and metabolic status of dairy cattle during the transition period in a freestall-housed dairy herd. J. Dairy Sci. 94:2883-2894. https://doi.org/10.3168/jds.2010-3855.

Cook, N. B. B., K. V. V. Nordlund, and G. R. R. Oetzel. 2004. Environmental influences on claw horn lesions associated with laminitis and subacute ruminal acidosis in dairy cows. J. Dairy Sci. 87:E36E46. https://doi.org/10.3168/jds.S0022-0302(04)70059-4.

De Marchi, M., M. Penasa, A. Zidi, and C. L. Manuelian. 2018. Invited review: Use of infrared technologies for the assessment of dairy products-Applications and perspectives. J. Dairy Sci. 101:1058910604. https://doi.org/10.3168/jds.2018-15202.

Denis-Robichaud, J., J. Dubuc, D. Lefebvre, and L. DesCôteaux. 2014. Accuracy of milk ketone bodies from flow-injection analysis for the diagnosis of hyperketonemia in dairy cows. J. Dairy Sci. 97:33643370. https://doi.org/10.3168/jds.2013-6744.

Enemark, J. M. D. 2008. The monitoring, prevention and treatment of sub-acute ruminal acidosis (SARA): A review. Vet. J. 176:32-43. https://doi.org/10.1016/j.tvjl.2007.12.021.

Fisher, R. A. 1915. Frequency distribution of the values of the correlation coefficient in samples from an indefinitely large population. Biometrika 10:507-521. https://doi.org/10.2307/2331838.

Fujiwara, K., H. Sawada, and M. Kano. 2012. Input variable selection for PLS modeling using nearest correlation spectral clustering. Chemom. Intell. Lab. Syst. 118:109-119. https://doi.org/10.1016/ j.chemolab.2012.08.007.

Gayen, A. K. 1951. The frequency distribution of the product-moment correlation coefficient in random samples of any size drawn from non-normal universes. Biometrika 38:219-247. https://doi.org/10 $.1093 /$ biomet/38.1-2.219.

Gengler, N. 2019. Symposium review: Challenges and opportunities for evaluating and using the genetic potential of dairy cattle in the new era of sensor data from automation. J. Dairy Sci. 102:57565763. https://doi.org/10.3168/jds.2018-15711.

Gengler, N., H. Soyeurt, F. Dehareng, C. Bastin, F. Colinet, H. Hammami, M.-L. Vanrobays, A. Lainé, S. Vanderick, C. Grelet, A. Vanlierde, E. Froidmont, and P. Dardenne. 2016. Capitalizing on fine milk composition for breeding and management of dairy cows. J. Dairy Sci. 99:4071-4079. https://doi.org/10.3168/jds.2015-10140.

Green, L. E., J. N. Huxley, C. Banks, and M. J. Green. 2014. Temporal associations between low body condition, lameness and milk yield in a UK dairy herd. Prev. Vet. Med. 113:63-71. https://doi.org/10 .1016/j.prevetmed.2013.10.009.

Grelet, C., C. Bastin, M. Gelé, J.-B. Davière, M. Johan, A. Werner, R. Reding, J. A. Fernandez Pierna, F. G. Colinet, P. Dardenne, N. Gengler, H. Soyeurt, and F. Dehareng. 2016. Development of Fourier transform mid-infrared calibrations to predict acetone, $\beta$-hydroxybutyrate, and citrate contents in bovine milk through a European dairy network. J. Dairy Sci. 99:4816-4825. https://doi .org/10.3168/jds.2015-10477.

Grelet, C., J. A. Fernández Pierna, P. Dardenne, V. Baeten, and F. Dehareng. 2015. Standardization of milk mid-infrared spectra from a European dairy network. J. Dairy Sci. 98:2150-2160. https://doi .org/10.3168/jds.2014-8764.

Grelet, C., A. Vanlierde, M. Hostens, L. Foldager, M. Salavati, K. L. Ingvartsen, M. Crowe, M. T. Sorensen, E. Froidmont, C. P. Ferris, C. Marchitelli, F. Becker, T. Larsen, F. Carter, and F. Dehareng. 2019. Potential of milk mid-IR spectra to predict metabolic status of cows through blood components and an innovative clustering approach. Animal. https://doi.org/10.1017/S1751731118001751.

Hamann, J., and V. Krömker. 1997. Potential of specific milk composition variables for cow health management. Livest. Prod. Sci. 48:201-208. https://doi.org/10.1016/S0301-6226(97)00027-4.

Heringstad, B., C. Egger-Danner, N. Charfeddine, J. E. Pryce, K. F. Stock, J. Kofler, A. M. Sogstad, M. Holzhauer, A. Fiedler, K. Müller, P. Nielsen, G. Thomas, N. Gengler, G. de Jong, C. Ødegård, 
F. Malchiodi, F. Miglior, M. Alsaaod, and J. B. Cole. 2018. Invited review: Genetics and claw health: Opportunities to enhance claw health by genetic selection. J. Dairy Sci. 101:4801-4821. https:// doi.org/10.3168/jds.2017-13531.

Misztal, I. 2008. BLUPF90 - a flexible mixed model program in Fortran 90. Accessed Jan. 20, 2020. http://nce.ads.uga.edu/ ignacy/ numpub/blupf90/docs/blupf90.pdf.

Jorjong, S., A. T. M. van Knegsel, J. Verwaeren, M. V. Lahoz, R. M. Bruckmaier, B. De Baets, B. Kemp, and V. Fievez. 2014. Milk fatty acids as possible biomarkers to early diagnose elevated concentrations of blood plasma nonesterified fatty acids in dairy cows. J. Dairy Sci. 97:7054-7064. https://doi.org/10.3168/jds.2014-8039.

Kirkpatrick, M., D. Lofsvold, and M. Bulmer. 1990. Analysis of the inheritance, selection and evolution of growth trajectories. Genetics 124:979-993. https://doi.org/10.1080/02640410903503640.

Kleen, J. L., L. Upgang, and J. Rehage. 2013. Prevalence and consequences of subacute ruminal acidosis in German dairy herds. Acta Vet. Scand. 55:48. https://doi.org/10.1186/1751-0147-55-48.

Köck, A., B. Fuerst-Waltl, J. Kofler, J. Burgstaller, F. Steininger, C. Fuerst, and C. Egger-Danner. 2019. Short communication: Use of lameness scoring to genetically improve claw health in Austrian Fleckvieh, Brown Swiss, and Holstein cattle. J. Dairy Sci. 102:1397-1401. https://doi.org/10.3168/jds.2018-15287.

Lim, P. Y., J. N. Huxley, J. A. Willshire, M. J. Green, A. R. Othman, and J. Kaler. 2015. Unravelling the temporal association between lameness and body condition score in dairy cattle using a multistate modelling approach. Prev. Vet. Med. 118:370-377. https:// doi.org/10.1016/j.prevetmed.2014.12.015.

Mineur, A., A. Köck, C. Grelet, N. Gengler, C. Egger-Danner, and J. Sölkner. 2017. First results in the use of milk mid-infrared spectra in the detection of lameness in Austrian dairy cows. Agric. Conspec. Sci. 82:163-166.

Onyiro, O. M., J. Offer, and S. Brotherstone. 2008. Risk factors and milk yield losses associated with lameness in Holstein-Friesian dairy cattle. Animal 2:1230-1237. https://doi.org/10.1017/ S1751731108002279.
Pryce, J. E., K. L. Parker Gaddis, A. Koeck, C. Bastin, M. Abdelsayed, N. Gengler, F. Miglior, B. Heringstad, C. Egger-Danner, K. F. Stock, A. J. Bradley, and J. B. Cole. 2016. Invited review: Opportunities for genetic improvement of metabolic diseases. J. Dairy Sci. 99:6855-6873. https://doi.org/10.3168/jds.2016-10854.

R Core Team. 2018. R: A language and environment for statistical computing. R Foundation for Statistical Computing, Vienna, Austria.

SAS Institute. 2017. SAS 9.4. SAS Institute Inc., Cary, NC.

Soyeurt, H., F. Dehareng, N. Gengler, S. McParland, E. Wall, D. P. P. Berry, M. Coffey, and P. Dardenne. 2011. Mid-infrared prediction of bovine milk fatty acids across multiple breeds, production systems, and countries. J. Dairy Sci. 94:1657-1667. https://doi.org/ 10.3168/jds.2010-3408.

Soyeurt, H., I. Misztal, and N. Gengler. 2010. Genetic variability of milk components based on mid-infrared spectral data. J. Dairy Sci. 93:1722-1728. https://doi.org/10.3168/jds.2009-2614.

Suthar, V. S., J. Canelas-Raposo, A. Deniz, and W. Heuwieser. 2013. Prevalence of subclinical ketosis and relationships with postpartum diseases in European dairy cows. J. Dairy Sci. 96:2925-2938. https://doi.org/10.3168/jds.2012-6035.

Van Haelst, Y. N. T., A. Beeckman, A. T. M. Van Knegsel, and V. Fievez. 2008. Short communication: Elevated concentrations of oleic acid and long-chain fatty acids in milk fat of multiparous subclinical ketotic cows. J. Dairy Sci. 91:4683-4686. https://doi .org/10.3168/jds.2008-1375.

van Knegsel, A. T. M., S. G. A. van der Drift, M. Horneman, A. P. W. de Roos, B. Kemp, and E. A. M. Graat. 2010. Short communication: Ketone body concentration in milk determined by Fourier transform infrared spectroscopy: Value for the detection of hyperketonemia in dairy cows. J. Dairy Sci. 93:3065-3069. https://doi .org/10.3168/jds.2009-2847.

Whitfield, R. G., M. E. Gerger, and R. L. Sharp. 1987. Near-infrared spectrum qualification via Mahalanobis Distance determination. Appl. Spectrosc. 41:1204-1213. https://doi.org/10.1366/ 0003702874447572 